\title{
UK gets rough ride over call for space cuts
}

London. An independent review of a satellite mission being planned by the European Space Agency (ESA) has concluded that, if different procedures had been adopted by both the agency and the scientific community, the estimated costs of the mission could have been reduced by between 10 and 15 per cent.

But the author of the study says he has found no evidence to support claims by British government officials that the overall costs of ESA's space science programme could be reduced by 25 per cent without a major impact on its activities' outcome.

The study was based on the proposed Satellite Test of the Equivalence Principle (STEP) mission, designed to test the assumed equivalence between the inertial and gravitational mass of bodies. It comes at a time when ESA is under pressure from several member states to find ways of saving money in its \$3.5-billion budget.

Some possible economies - such as a 20 per cent reduction in permanent staff - are said to have been outlined in two recent audits of the agency, one by the management consultants Andersen Consulting, the other by Price Waterhouse, which were delivered last month.

ESA science missions are generally accepted to be well managed and run in a relatively cost-conscious way. But even agency officials acknowledge that ways of reducing costs might be found, for example by increasing the accuracy of studies at an early stage in the planning of missions.

Their efforts have been endorsed by ESA's principal advisory panel, its science programme committee (SPC). Last week, the members of the committee agreed unanimously on the need for enhanced efficiency in the agency, given increased demands from the scientific community and budgetary pressures in various member states.

David Southwood, professor of physics at Imperial College, London, and chairman of the committee, says that a "large majority" of its members, meeting in Paris, favoured consolidating such efficiency gains into the scientific programme.

The main exception is Britain, which is seeking a 25 per cent cut in its subscription to ESA over the next five years, arguing that its current subscription now dominates its space budget, thus undermining its national and binational space activities.

Defending Britain's position, Sir John Cadogan, the director general of research councils, claims it was largely UK pressure that led to a reduction of 1 billion Swiss francs (US $\$ 860$ million) in the projected costs of building the Large Hadron Collider at the European Laboratory for Particle Physics.

Officials from the UK Particle Physics and Astronomy Research Council are now pointing to the study of the STEP mission, carried out by Mike Cruise of the University of Sheffield at the invitation of ESA, as evidence that cuts of a comparable magnitude are feasible in the space agency.

In particular, much is being made of the difference between the figure of 426 million accounting units - roughly $\$ 550$ million that has been used as an initial estimate by ESA of the costs of the mission, and the 294 m.a.u. that Cruise claims it could cost under different circumstances.

But Cruise himself acknowledges that some of his assumptions - for example, that salary costs would be the 'mean' of those in national space laboratories, not for ESA staff - are unrealistic under present ESA rules, while the space agency's figure has a built-in margin of error.

A fairer comparison, he suggests, is between his figure, perhaps adjusted slightly upwards, and one closer to the 345 million accounting units that ESA officials have been set as the target cost of STEP, a net difference of 10 to 15 per cent. "My study has shown that there are modest savings available within the ESA system, but I have found no justification that these could be as high as 25 per cent," says Cruise.

Coincidentally - but perhaps significantly - the reduction Cruise says would be feasible is close to that being proposed by Germany for ESA's space science programmes. This would be the result of adopting Germany's suggestion that the budget be

kept level in cash terms for the next five years - that is, would shrink in real terms by the amount of inflation.

Germany, like Britain, is facing pressures on its domestic space budget as a result of economic difficulties. But it is also facing the need to fulfil its commitment to play a significant role in the international space station, to which any savings in the space science budget might be directed.

In contrast, France and some other ESA member states - several of whom pay their subscriptions out of their budgets for industry rather than for research - are insisting that any savings produced through increased efficiency should be fed back into the space science programmes themselves.

Britain's position is very different. Indeed, PPARC has given no commitment that savings in Britain's contribution to ESA's science programmes would be reallocated to the domestic space programme, leading to fears that the money would be used for other research sponsored by the research council, for example in particle physics of ground-based astronomy.

The fact that Germany's proposals go half-way towards Britain's demands indicates that room exists for compromise. But the gap is still substantial, and bridging it will require a political accommodation that is unlikely to materialize before Europe's space ministers meet in October.

David Dickson

\section{US and India sign ocean data deal}

New Delhi. The Indian government, having refused for almost eight years to provide the United States with 'real-time' weather data gathered by its INSAT satellites over the Indian Ocean, last week agreed to do so - but only under certain conditions.

India has three communications satellites in geostationary orbits, each equipped to collect cloud and weather data. The United States has, since 1986, been asking for half-hourly data which, it says, are essential for climate-modelling and weather forecasting. But after objections from the Indian military authorities, the Indian Meteorological Department has been supplying only low-resolution, oneday-old data recorded on magnetic tapes.

Officials had argued that highresolution data could be used to extract information on ship and aircraft movements in the Indian Ocean. Some government scientists are also known to believe that meteorological data about the Indian monsoon are too sensitive to be shared with other countries because of their potential commercial implications.

But last week James Dodge, head of the Mission to Planet Earth office at the
National Aeronautics and Space Administration (NASA), and the chairman of the Indian Space Commission, K. Kasturirangan, signed a 'statement of intent' to exchange INSAT data with that from US weather satellites.

According to government officials, India has now agreed to provide real-time INSAT data on a 'need-to-know' basis. US scientists will have to propose specific projects that justify the need for such data, which will be released only after projects have been approved by the Indian side.

The data will be provided only for the duration of specific projects, and will be transferred through a high-speed telecommunications link. India has insisted that NASA should not disseminate the data, and use them only for specified purposes.

In exchange, the United States has offered to share data from its Tropical Rainfall Measurement Mission satellites, which will provide rainfall measurements over the entire tropics, and help India enhance its monsoon forecasting. India will also gain access to archival climate and weather data maintained by NASA since 1978.

K.S. Jayaraman 